\title{
Assessment of pain response in capsaicin-induced dynamic mechanical allodynia using a novel and fully automated brushing device
}

\author{
Kristian G du Jardin MSc ${ }^{1}$, Lise S Gregersen $\mathrm{MSc}^{1}$, Turid Røsland $\mathrm{MSc}^{1}$, Kathrine H Uggerhøj MSc ${ }^{1}$, \\ Lars J Petersen MD DMSc ${ }^{1,2}$, Lars Arendt-Nielsen PhD DMSc ${ }^{1}$, Parisa Gazerani PharmD PhD ${ }^{1}$
}

\begin{abstract}
KG du Jardin, LS Gregersen, T R $\phi$ sland, et al. Assessment of pain response in capsaicin-induced dynamic mechanical allodynia using a novel and fully automated brushing device. Pain Res Manag 2013;18(1):6-10.
\end{abstract}

BACKGROUND: Dynamic mechanical allodynia is traditionally induced by manual brushing of the skin. Brushing force and speed have been shown to influence the intensity of brush-evoked pain. There are still limited data available with respect to the optimal stroke number, length, force, angle and speed. Therefore, an automated brushing device (ABD) was developed, for which brushing angle and speed could be controlled to enable quantitative assessment of dynamic mechanical allodynia.

OBJECTIVES: To compare the ABD with manual brushing using capsaicin-induced allodynia, and to investigate the role of stroke angle and speed on pain intensity.

METHODS: Experimental dynamic mechanical allodynia was induced by an intradermal injection of capsaicin $(100 \mu \mathrm{g})$ into the volar forearm of 12 healthy, male volunteers. Dynamic mechanical allodynia was rated on a $10 \mathrm{~cm}$ visual analogue scale (VAS) after each set of strokes at angles of $30^{\circ}$, $60^{\circ}$ and $90^{\circ}$ with speeds of $17 \mathrm{~mm} / \mathrm{s}, 21 \mathrm{~mm} / \mathrm{s}$ and $25 \mathrm{~mm} / \mathrm{s}$ for each angle. A two-way ANOVA with repeated measures was performed to assess the influence of brushing parameters. To evaluate test-retest reliability, BlandAltman 95\% limits of agreement, including a coefficient of repeatability and an intraclass correlation coefficient (ICC), were determined.

RESULTS: The angle and speed exhibited a significant impact on pain intensity $(\mathrm{P}<0.001$ and $\mathrm{P}<0.015$, respectively). Post hoc analysis showed that the highest pain intensity was recorded with an angle of $30^{\circ}$ regardless of brushing speed. The ABD demonstrated superior test-retest reliability (coefficient of repeatability $=1.9 \mathrm{VAS} ; \mathrm{ICC}=0.91)$ compared with manual brushing (coefficient of repeatability $=2.8$ VAS; ICC $=0.80 ; \mathrm{P}<0.05)$. The most reliable combination of parameters (coefficient of repeatability $=1.3$ VAS; ICC $=0.97$ ) was an angle of $60^{\circ}$ and a speed of $21 \mathrm{~mm} / \mathrm{s}$.

CONCLUSIONS: A controlled, automatic brushing method can be used for quantitative investigations of allodynic reactions, and is more reliable for quantitative assessment of dynamic mechanical allodynia compared with traditional manual brushing.

Key Words: Capsaicin; Dynamic mechanical allodynia; Human experimental pain model; Test-retest reliability

\section{Lévaluation des réponses à la douleur en cas d'allodynie mécanique dynamique induite par la capsaïcine au moyen d'un nouvel appareil de brossage entièrement automatisé}

HISTORIQUE : D'ordinaire, l'allodynie mécanique dynamique est déterminée par brossage manuel de la peau. Il est établi que la force et la vitesse du brossage influent sur l'intensité de la douleur évoquée par brossage. Les données sur le nombre, la durée, la force et la vitesse des mouvements de brossage demeurent limitées. Ainsi, les chercheurs ont mis au point un appareil de brossage automatisé (ABA) grâce auquel il est possible de contrôler l'angle et la vitesse du brossage en vue de procéder à une évaluation de l'allodynie mécanique dynamique.

OBJECTIF : Comparer l'ABA par brossage manuel au moyen d'allodynie induite par la capsaïcine et examiner le rôle de l'angle et de la vitesse des mouvements de brossage sur l'intensité de la douleur évoquée.

MÉTHODOLOGIE : Les chercheurs ont induit une allodynie mécanique dynamique expérimentale par injection intradermique de capsaïcine $(100 \mu \mathrm{g})$ dans le muscle palmaire de l'avant-bras de 12 hommes volontaires en bonne santé. Ils ont évalué l'allodynie mécanique dynamique sur une échelle analogique visuelle (ÉAV) de $10 \mathrm{~cm}$ après chaque série de mouvements de brossage, à des angles de $30^{\circ}, 60^{\circ}$ et $90^{\circ}$ et des vitesses de $17 \mathrm{~mm} / \mathrm{s}, 21 \mathrm{~mm} / \mathrm{s}$ et $25 \mathrm{~mm} / \mathrm{s}$ à chaque angle. Ils ont effectué une analyse de variance avec reprise des mesures pour évaluer l'influence des paramètres de brossage. Afin d'évaluer la fiabilité test-retest, ils ont déterminé les limites de concordance à $95 \%$ à l'aide d'un graphique de Bland-Altman, y compris un coefficient de répétabilité et un coefficient de corrélation intraclasse (CCI).

RÉSULTATS : L'angle et la vitesse avaient d'importantes répercussions sur l'intensité de la douleur ( $\mathrm{P}<0,05$ et $\mathrm{P}<0,015$, respectivement). L'analyse $a$ posteriori a révélé que la douleur la plus forte était enregistrée à un angle de $30^{\circ}$, quelle que soit la vitesse du brossage. L'ABA a démontré une plus grande fiabilité test-retest (coefficient de répétabilité $=1,9$ ÉAV; $C C I=0,91$ ) que le brossage manuel (coefficient de répétabilité $=2,8$ ÉAV; $\mathrm{CCI}=0,80 ; \mathrm{P}<0,05$ ). La combinaison de paramètres la plus fiable (coefficient de répétabilité $=1,3$ ÉAV; CCI=0,97) était un angle de $60^{\circ}$ et une vitesse de $21 \mathrm{~mm} / \mathrm{s}$.

CONCLUSIONS : Une méthode de brossage automatisé contrôlée peut être utilisée pour procéder à l'examen quantitatif des réactions d'allodynie et est plus fiable que le brossage manuel classique pour procéder à l'évaluation quantitative de l'allodynie mécanique dynamique.
$\mathrm{N}$ europathic pain affects $7 \%$ to $8 \%$ of the general population, with variable and often unsatisfactory response to available treatments (1-4). In addition to spontaneous pain, patients with neuropathic pain experience pain due to light, moving mechanical stimuli, referred to as dynamic mechanical allodynia. In one study, dynamic mechanical allodynia occurred in $22 \%$ of patients with painful traumatic peripheral neuropathy (5). This phenomenon has a considerable impact on the quality of life and sleep patterns of patients (6), and is difficult to manage pharmacologically. The pathophysiology of dynamic mechanical allodynia remains largely unknown, but depends on the condition and can involve peripheral and central sensitization and descending facilitation $(6,7)$.

Dynamic mechanical allodynia can be assessed using simple tools such as a manual handheld brush or a cotton swab. Some publications provide recommendations for dynamic mechanical allodynia assessment (8), but there is no uniform consensus with respect to stroke number, length, force, duration, speed, frequency or intervals between stimulations (9). To the best of our knowledge, only two studies have investigated the influence of stroke length, number of strokes, speed and force on dynamic mechanical allodynia $(10,11)$. These studies

${ }^{1}$ Department of Health Science and Technology, Faculty of Medicine, Aalborg University; ${ }^{2}$ Department of Nuclear Medicine, Aalborg Hospital, Aalborg, Denmark

Correspondence: Dr Parisa Gazerani, Center for Sensory-Motor Interaction, Department of Health Science and Technology, Faculty of Medicine, Aalborg University, Fredrik Bajers Vej 7-D3, 9220 Aalborg, Denmark. Telephone 45-99-40-24-12, fax 45-98-15-40-08,

e-mail gazerani@hst.aau.dk 


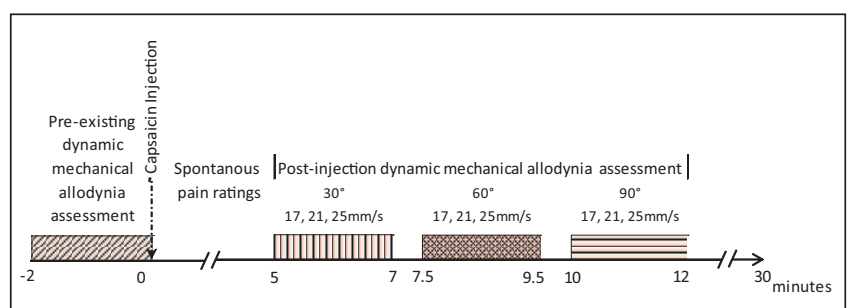

Figure 1) The design of study sessions. Sessions 1 and 2 were identical for each subject.

used a semiquantitative method, and the influence of the individual who applied the method may not have been entirely eliminated.

There is a need for an automated method to assess dynamic mechanical allodynia with minimal impact of the investigator and with high reproducibility. The aim of the present study was to develop and apply a novel, fully automated brushing device (ABD) for which the angle and speed of stroking could be controlled, making it possible to compare evoked responses and method reliability. To test the ABD, allodynia was induced by intradermal capsaicin injection to mimic the clinical condition (12-14).

\section{Subjects}

\section{METHODS}

Twelve healthy male volunteers (21 to 26 years of age) participated in the present study. None of the subjects suffered from any neurological, dermatological, allergic or psychiatric disorders. Consumption of medication, alcohol, caffeine and tobacco was prohibited for $24 \mathrm{~h}$ before the test session. The study was approved by the local ethics committee (N-20110058) and conducted according to the Declaration of Helsinki and guidelines of the International Association for the Study of Pain (15). All volunteers provided oral and written informed consent before the study.

\section{Study design}

The study consisted of two identical sessions separated by one week, and each session was designed as follows. First, a baseline evaluation was undertaken before the injection of capsaicin (no allodynia was present). Capsaicin was then injected in randomized order to the left or right forearm, and the evoked pain associated with this injection was allowed to subside completely ( $5 \mathrm{~min}$ ) before dynamic mechanical allodynia was assessed using either the ABD or manual brushing (Figure 1). Thirty minutes after the initial dosing, capsaicin was injected into the other arm, and the procedure was repeated using the other method. The sequence and combination of forearm (left/right) and method (ABD/manual brushing) were randomized. All assessments were performed at the same time of day. The room temperature was constant and the same investigator performed all assessments.

\section{Intradermal capsaicin}

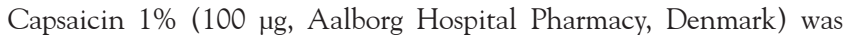
injected intradermally. The site of the injection was the midpoint between the elbow and the wrist at the volar aspect of the forearm. The subjects continuously rated the spontaneous pain intensity on an electronic visual analogue scale (VAS) for 5 min following the injection. Each subject was carefully instructed to focus solely on the sensory element (intensity) of the pain experience. To rate pain intensity, the participants moved a vertically sliding indicator along the $10 \mathrm{~cm}$ VAS, labelled with a lower marker of 'no pain' and an upper marker of 'maximum pain', and data were recorded electronically.

\section{Assessment of dynamic mechanical allodynia}

Subjects were seated with their forearms lying on the laboratory desk with the volar sides facing up. The custom-made ABD (Figure 2) consisted of a brush (Senselab brush number 5, length $210 \mathrm{~mm}$, width $15 \mathrm{~mm}$, thickness $5 \mathrm{~mm}$; Somedic AB, Sweden) attached to a movable platform (Aalborg University, Aalborg, Denmark). An electric motor

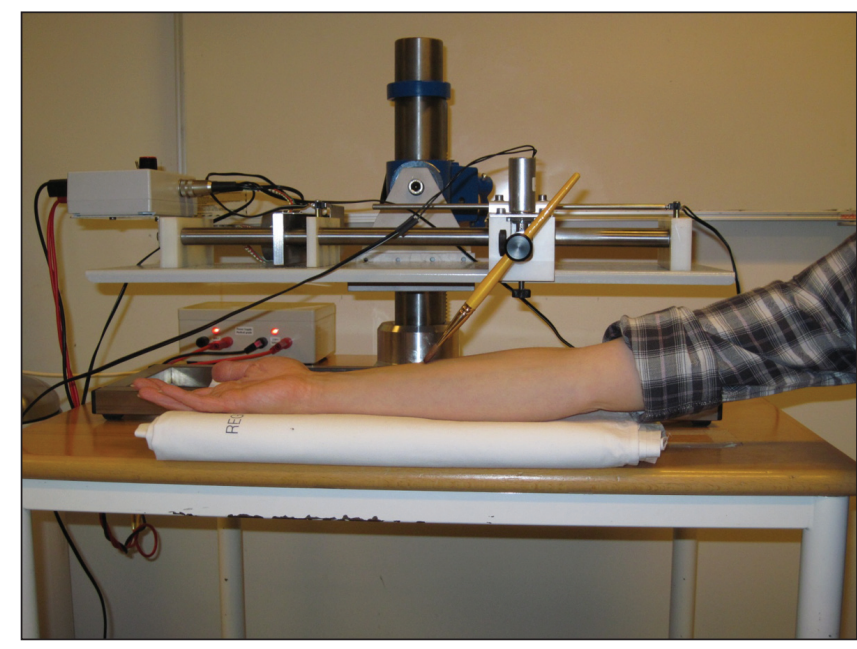

Figure 2) The custom-made automated brushing device comprised a brush attached to a movable platform. An electric motor moved the platform in a linear horizontal motion. The angle and speed of the brush was adjustable.

moved the platform in a linear horizontal motion. The angle and speed of the brush could be adjusted. Each stroke was $4.5 \mathrm{~cm}$ in length and was applied in the proximal to distal direction with the midpoint of the stroke being the capsaicin injection site. The strokes were applied in nine different stimulus settings comprising speeds of $17 \mathrm{~mm} / \mathrm{s}, 21 \mathrm{~mm} / \mathrm{s}$ and $25 \mathrm{~mm} / \mathrm{s}$ combined with angles of $30^{\circ}, 60^{\circ}$ and $90^{\circ}$. One angle was studied with all speeds before the ABD was set to the next angle. The order of angles and speeds are shown in Figure 1. Each setting was repeated three times, after which the subjects were asked to rate the mean pain intensity of dynamic mechanical allodynia on the VAS. The subjects were carefully instructed to rate the intensity of dynamic mechanical allodynia separated from any spontaneous pain. The completion of three repetitions for each setting took approximately $10 \mathrm{~s}$ and was followed by a break of $30 \mathrm{~s}$. The manual assessment of dynamic mechanical allodynia used the same brush and was performed at the same angles and speeds as investigated by the ABD.

\section{Statistics}

Any 'outliers' or spurious data were eliminated using Grubbs' test. Normal distribution of data was assessed using the Kolmogorov-Smirnov test of normality. Homoscedasticity was evaluated by means of a correlation coefficient between absolute differences and individual means and by visually observing the plot for a 'funnel shape'. A two-way ANOVA with repeated measures on two factors (angle and speed) was used to analyze the total brush-evoked pain intensity. Post hoc comparisons of significant ANOVA results were analyzed using the Sidák correction. Data are presented as mean \pm SD unless otherwise indicated.

Test-retest reliability of VAS scores was assessed using the method of Bland and Altman including a 95\% coefficient of repeatability. A paired $t$ test was performed on the mean coefficient of repeatability of each angle and speed combination for ABD and manual brushing. Additionally, an intraclass correlation coefficient (ICC) 2.1 was calculated and interpreted according to established grading criteria: ICC $<0.20$ poor, 0.21 to 0.40 fair, 0.41 to 0.60 moderate, 0.61 to 0.80 good and 0.81 to 1.00 very good (16). Differences were considered to be statistically significant at $\mathrm{P}<0.05$.

Data were analyzed using PASW Statistics version 18.0 (IBM Corporation, USA) and Microsoft Excel 2010 (Microsoft Corporation, USA).

\section{RESULTS}

All subjects completed both experimental sessions. Data from one subject were excluded from the analyses due to highly abnormal pain ratings at one session. No pre-existing dynamic mechanical allodynia was observed in any subjects at baseline. The spontaneous pain 


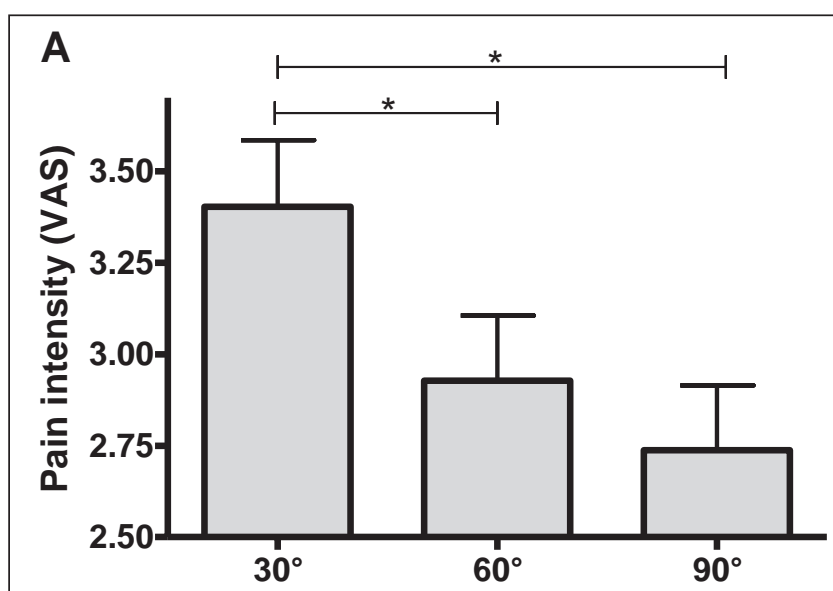

B

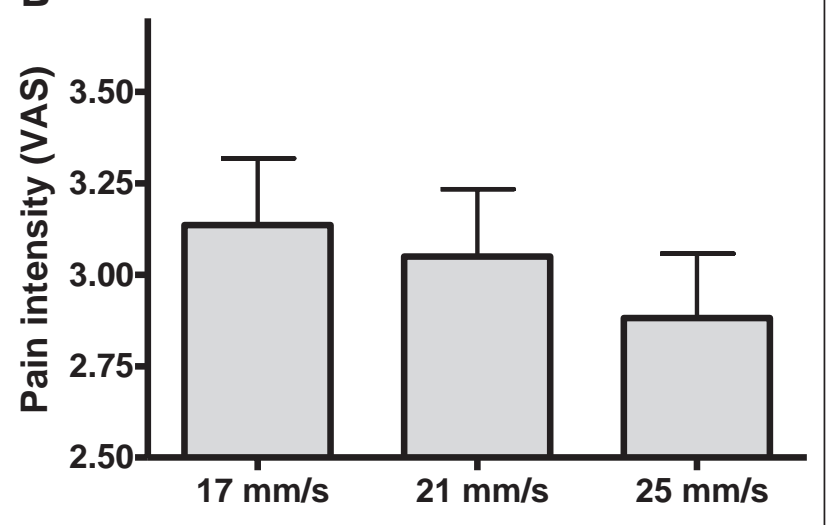

Figure 3) Pain intensity (mean \pm SD on a $10 \mathrm{~cm}$ visual analogue scale [VAS]) of dynamic mechanical allodynia according to different brushing angles (A) and speeds (B). The data are the sum of recordings obtained by an automated brushing device and manual methods. $* P<0.05$

vanished rapidly after the capsaicin injection and reached a VAS score of $1.2 \pm 0.2$ at $5 \mathrm{~min}$ after the injection.

\section{Intensity of dynamic mechanical allodynia and the influence of brushing angle and speed}

All subjects reported capsaicin-induced dynamic mechanical allodynia in both sessions. The raw data failed to show normal distribution, but the data were successfully square root transformed for parametric statistical analysis. The pain intensities are presented in Figure 3, with details shown in Table 1.

Two-way ANOVA showed a significant impact of angle on pain intensity $(\mathrm{P}<0.001)$. Post hoc comparisons showed significant differences between $30^{\circ}$ and $60^{\circ}$ and between $30^{\circ}$ and $90^{\circ}$, with the highest pain ratings for $30^{\circ}$. Speed also showed significant impact on pain intensity $(\mathrm{P}<0.015)$ with no significant differences among individual brushing speeds.

\section{Test-retest reliability of dynamic mechanical allodynia}

The results of the test-retest reliability analyses for ABD and manual brushing are summarized in Table 2 and Figure 4. Overall, the lowest coefficients of repeatability and highest ICCs were found with the $\mathrm{ABD}$ (coefficient of repeatability $=1.9 \mathrm{VAS}$; $\mathrm{ICC}=0.91$ ) versus manual brushing (coefficient of repeatability $=2.8$ VAS; $\mathrm{ICC}=0.80$ ). The group mean coefficient of repeatability with ABD was significantly inferior $(\mathrm{P}<0.05)$ to manual brushing. The most reliable combination of parameters for the ABD was found to be an angle of $60^{\circ}$ and speed of $21 \mathrm{~mm} / \mathrm{s}$ (coefficient of repeatability = $1.3 \mathrm{VAS}$; $\mathrm{ICC}=0.97$ ).

\section{DISCUSSION}

The present study demonstrated that pain intensity provoked during experimentally-induced allodynia depends on brushing angle and speed.

Patients with neuropathic pain not only experience spontaneous pain, but also suffer from dynamic mechanical allodynia, which has a high impact on their quality of life (17). Studies focusing on treatment options for neuropathic pain have mainly monitored spontaneous pain, and assessment of dynamic mechanical allodynia is often not included (18). Therefore, it is important that a precise, valid and standard method is developed to evaluate dynamic mechanical allodynia in experimental pain studies, in profiling patients and in trials for new treatment modalities.

The present study introduced a quantitative, automatic method of studying dynamic mechanical allodynia. The ABD method evoked dynamic mechanical allodynia comparable with that from manual brushing; however, the reproducibility was significantly superior to manual brushing. A semiquantitative manual brushing method has previously been used in patients with peripheral neuropathic pain $(10,19)$. In these studies, the brush was fitted to an electronic force transducer and applied manually by the investigator. Data from these studies have consistently indicated that increased brushing length, number of strokes and stroke force significantly increased the brushevoked pain intensity. In addition, there is a relationship between pain intensity and stroke speed (11). These studies, however, used area under the curve as an indicator for pain intensity, in contrast to the point-in-time recordings used in the present study. The area under the curve includes the time aspect of pain perception and is, therefore, confounded when comparing stimuli of different durations such as stroke speed, length and number of strokes. Although a semiquantitative technique was superior to manual brushing in terms of repeatability (19), this technique does not fully eliminate the influence of the investigator. A fully automated brushing device that displayed significantly superior reliability in evoking dynamic mechanical allodynia compared with a manual brushing procedure was, therefore, introduced in the present study. Although a comparison of the fully automated method with the semiquantitative method may yield additional valuable information, any meaningful analysis is prevented by methodological differences (eg, neuropathic pain patients versus healthy volunteers), and additional studies in which the different techniques are compared under the same conditions are required. Studies in healthy volunteers have demonstrated an increased number of action potentials and duration of brush-evoked activity in myelinated $A \beta$ fibres with decreasing brushing speed $(20,21)$. Furthermore, we found that a decreased angle of stroking increased dynamic mechanical allodynia. One could speculate that this finding is explained by convergence of increased activity in $A \beta$ afferents. However, because the stroke was performed in both the primary and secondary hyperalgesic area $(4.5 \mathrm{~cm}$ length) in the present study, other fibres may also have an impact. Reduction of stroking length (eg, to $2 \mathrm{~cm}$ ) can be helpful to focus either on the primary or secondary hyperalgesic area, but this will generally result in lower pain intensities.

In the present study, we did not randomize the order of the application of the different speeds and angles because such randomization would render the test-retest reliability very complicated. Thus, one could argue that the results are biased by time factors. However, our findings remain consistent with results from previous studies. Furthermore, one may speculate that the spontaneous pain and dynamic mechanical allodynia facilitates an increased response in the contralateral arm. It is known that contralateral spreading of sensitization can be detected after capsaicin injection (22). Thus, a single-arm design may be preferred. Such a design would require a substantial increase in the time between injections to allow dynamic mechanical allodynia to disappear, which may bias the test-retest reliability analysis. This bias, along with the fact that randomization prevents any effect on the testretest reliability of dynamic mechanical allodynia, dictated a two-arm design with a very short interval between injections. As a consequence, 
TABLE 1

Dynamic mechanical allodynia intensity assessed using the automated brushing device (ABD) and manual brushing (MB) at different angles and velocities

\begin{tabular}{|c|c|c|c|c|c|c|c|c|c|c|}
\hline & & \multicolumn{9}{|c|}{ Angle/speed, mm/s } \\
\hline & & $30 \% / 17$ & $30 \% / 21$ & $30 \% / 25$ & $60 \% / 17$ & $60 \% / 21$ & $60 \% / 25$ & $90 \% / 17$ & $90 \% / 21$ & $90 \% / 25$ \\
\hline \multirow[t]{2}{*}{ Session 1} & ABD (Visual analogue scale) & $3.6 \pm 2.1$ & $3.8 \pm 2.3$ & $3.7 \pm 2.1$ & $3.1 \pm 2.0$ & $3.2 \pm 2.2$ & $2.9 \pm 2.2$ & $2.7 \pm 2.3$ & $2.6 \pm 2.1$ & $2.5 \pm 1.9$ \\
\hline & MB (Visual analogue scale) & $3.5 \pm 1.9$ & $3.4 \pm 2.1$ & $2.8 \pm 2.0$ & $2.7 \pm 1.8$ & $2.7 \pm 1.8$ & $2.4 \pm 1.7$ & $2.8 \pm 1.9$ & $2.5 \pm 1.7$ & $2.3 \pm 1.7$ \\
\hline \multirow[t]{2}{*}{ Session 2} & ABD (Visual analogue scale) & $3.5 \pm 2.3$ & $3.1 \pm 2.1$ & $3.1 \pm 1.9$ & $3.1 \pm 2.1$ & $3.0 \pm 2.2$ & $2.8 \pm 2.1$ & $2.8 \pm 2.0$ & $3.0 \pm 2.2$ & $3.0 \pm 2.4$ \\
\hline & MB (Visual analogue scale) & $3.6 \pm 2.2$ & $3.5 \pm 2.4$ & $3.3 \pm 2.4$ & $3.1 \pm 2.5$ & $3.1 \pm 2.5$ & $3.1 \pm 2.3$ & $3.0 \pm 2.6$ & $2.8 \pm 2.3$ & $2.7 \pm 2.1$ \\
\hline
\end{tabular}

Data presented as mean $\pm S D$

TABLE 2

Reliability of different parameter combinations of the automated brushing device and manual brushing procedures*

\begin{tabular}{|c|c|c|c|c|c|c|}
\hline \multirow[b]{2}{*}{$\begin{array}{l}\text { Automated brushing device, } \\
\text { angle/speed, } \mathrm{mm} / \mathrm{s}\end{array}$} & \multicolumn{4}{|c|}{ Bland-Altman $95 \%$ limits of agreement } & \multicolumn{2}{|c|}{ ICC 2.1} \\
\hline & $\begin{array}{l}\text { Upper limit } \\
\text { (VAS) }\end{array}$ & $\begin{array}{l}\text { Mean difference } \\
\text { (VAS) }\end{array}$ & $\begin{array}{l}\text { Lower limit } \\
\text { (VAS) }\end{array}$ & $\begin{array}{c}\text { Coefficient of } \\
\text { repeatability (VAS) }\end{array}$ & ICC & $95 \% \mathrm{Cl}$ \\
\hline Session 1 - Session 2: 30\%17 & 2.1 & 0.0 & -2.0 & 2.0 & 0.91 & $0.71-0.98$ \\
\hline Session 1 - Session 2: 30\%/21 & 2.6 & 0.6 & -1.3 & 2.3 & 0.90 & $0.59-0.97$ \\
\hline Session 1 - Session 2: 30\%/25 & 2.3 & 0.6 & -1.1 & 2.0 & 0.88 & $0.55-0.97$ \\
\hline Session 1 - Session 2: $60 \% 17$ & 1.8 & 0.0 & -1.8 & 1.7 & 0.94 & $0.78-0.98$ \\
\hline Session 1 - Session 2: 60\%/21 & 1.5 & 0.2 & -1.2 & 1.3 & 0.97 & $0.88-0.99$ \\
\hline Session 1 - Session 2: 60\%/25 & 1.7 & 0.1 & -1.6 & 1.6 & 0.93 & $0.76-0.98$ \\
\hline Session 1 - Session 2: 90\%17 & 2.1 & -0.1 & -2.2 & 2.0 & 0.91 & $0.70-0.98$ \\
\hline Session 1 - Session 2: 90\%/21 & 1.4 & -0.4 & -2.1 & 1.8 & 0.91 & $0.72-0.98$ \\
\hline Session 1 - Session 2: 90\%/25 & 1.6 & -0.5 & -2.7 & 2.3 & 0.84 & $0.54-0.96$ \\
\hline
\end{tabular}

\begin{tabular}{|c|c|c|c|c|c|c|}
\hline \multirow[b]{2}{*}{ Manual brushing, angle/speed, $\mathrm{mm} / \mathrm{s}$} & \multicolumn{4}{|c|}{ Bland-Altman $95 \%$ limits of agreement } & \multicolumn{2}{|c|}{ ICC 2.1} \\
\hline & $\begin{array}{l}\text { Upper limit } \\
\text { (VAS) }\end{array}$ & $\begin{array}{l}\text { Mean difference } \\
\text { (VAS) }\end{array}$ & $\begin{array}{l}\text { Lower limit } \\
\text { (VAS) }\end{array}$ & $\begin{array}{c}\text { Coefficient of } \\
\text { repeatability (VAS) }\end{array}$ & ICC & $95 \% \mathrm{Cl}$ \\
\hline Session 1 - Session 2: 30\%/17 & 2.0 & -0.2 & -2.4 & 2.1 & 0.89 & $0.65-0.97$ \\
\hline Session 1 - Session 2: 30\%/25 & 2.1 & -0.4 & -2.9 & 2.5 & 0.87 & $0.60-0.96$ \\
\hline Session 1 - Session 2: 60\%17 & 2.5 & -0.4 & -3.3 & 2.9 & 0.75 & $0.29-0.93$ \\
\hline Session 1 - Session 2: 60\%/21 & 2.4 & 0.4 & -3.2 & 2.8 & 0.81 & $0.44-0.95$ \\
\hline Session 1 - Session 2: 90\%17 & 3.8 & -0.2 & -4.1 & 3.8 & 0.72 & $0.23-0.92$ \\
\hline Session 1 - Session 2: 90\%/21 & 2.9 & -0.3 & -3.5 & 3.1 & 0.74 & $0.27-0.92$ \\
\hline Session 1 - Session 2: 90\%/25 & 2.2 & -0.4 & -3.0 & 2.6 & 0.77 & $0.34-0.93$ \\
\hline
\end{tabular}

${ }^{*}$ Test-retest reliability was assessed using the intraclass correlation coefficient (ICC) 2.1 and Bland-Altman 95\% limits of agreement, providing a coefficient of repeatability. VAS Visual analogue scale

the absolute pain ratings presented in Table 1 may be slightly overestimated.

The German Research Network on Neuropathic Pain has provided a standard protocol for the quantitative sensory testing of dynamic mechanical allodynia in neuropathic patients (8). The present study differs somewhat from these guidelines with regard to the brushing length ( $4.5 \mathrm{~cm}$ in the present study versus $2 \mathrm{~cm}$ in the guidelines). The increased length of stroking followed by increased spatial activation in the current methodology may increase the pain intensity (10) and alter the reliability. Therefore, the brushing length producing the most reliable dynamic mechanical allodynia should be determined and standardized.

Most previous studies have used the ICC or Pearson correlation coefficient to demonstrate validity or reliability (23), although the methods have been subject to criticism. Both methods include the variance term for individuals and are, therefore, affected by sample heterogeneity to such a degree that a high correlation may still indicate unacceptable reliability (24). This complicates study interpretation and interstudy comparison. Therefore, the previous suggestions (25) were followed, and Bland-Altman 95\% limits of agreement were applied, providing a coefficient of repeatability that can strongly demonstrate reliability that is less affected by sample heterogeneity. As further advocated, an ICC 2.1 was also introduced.

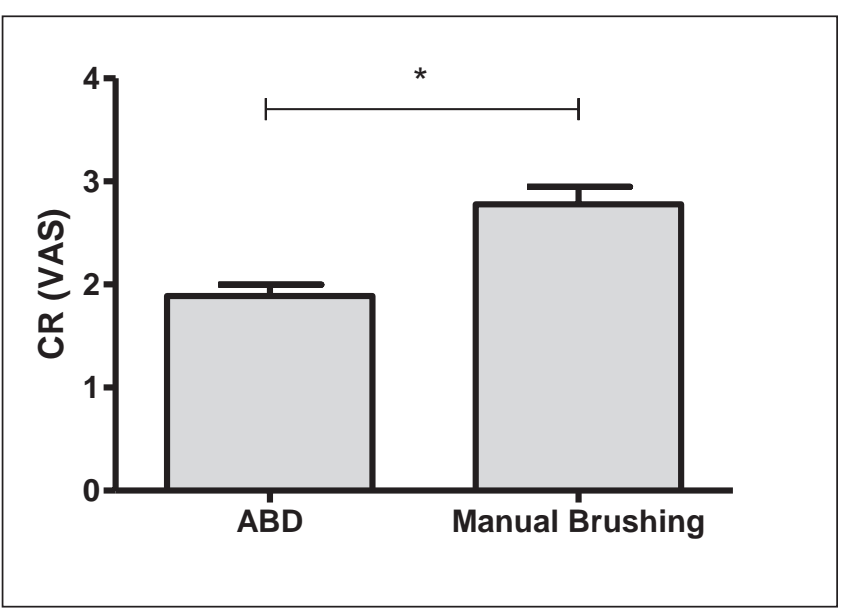

Figure 4) Group mean coefficient of repeatability (CR) for the automated brushing device $(A B D)$ and manual brushing. $* P<0.05$. VAS Visual analogue scale 


\section{CONCLUSION}

The present study introduced an ABD for the measurement of pain due to dynamic mechanical allodynia. The method appeared to be superior to manual brushing, and the relationship between brushing angle and speed and intensity of evoked allodynic pain was determined. The highest pain intensity was evoked with $30^{\circ}$, and the most reliable combination of parameters was a brush angle of $60^{\circ}$ and a speed of $21 \mathrm{~mm} / \mathrm{s}$. Additional investigation of brushing parameters should be performed to further optimize the method.

ACKNOWLEDGEMENTS: The authors are grateful to Carsten Dahl Mørch PhD, and Jose A Biurrun Manresa PhD, for their contributions to the statistical analyses, and Leif Jepsen and Knud Larsen for their excellent technical assistance. An abstract of this work was presented at the meeting of the European Federation of International Association for the Study of Pain Chapters, 2011.

CONFLICTS OF INTEREST: The authors have no conflicts of interest to declare with regard to the present study.

AUTHOR CONTRIBUTIONS: The authors shared contributions to conduct experiments, analyze data and prepare the manuscript for the present study. All authors discussed the results and commented on the manuscript.

\section{REFERENCES}

1. Baron R, Binder A, Wasner G. Neuropathic pain: Diagnosis, pathophysiological mechanisms, and treatment. Lancet Neurol 2010;9:807-19.

2. Bouhassira D, Lanteri-Minet M, Attal N, Laurent B, Touboul C. Prevalence of chronic pain with neuropathic characteristics in the general population. Pain 2008;136:380-7.

3. Torrance N, Smith BH, Bennett MI, Lee AJ. The epidemiology of chronic pain of predominantly neuropathic origin. Results from a general population survey. J Pain 2006;7:281-9.

4. Baron R, Binder A, Wasner G. Neuropathic pain: Diagnosis, pathophysiological mechanisms, and treatment. Lancet Neurol 2010;9:807-19.

5. Leffler AS, Hansson P. Painful traumatic peripheral partial nerve injury-sensory dysfunction profiles comparing outcomes of bedside examination and quantitative sensory testing. Eur J Pain 2008;12:397-402.

6. Hansson P. Difficulties in stratifying neuropathic pain by mechanisms. Eur J Pain 2003;7:353-7.

7. Woolf CJ, Mannion RJ. Neuropathic pain: Aetiology, symptoms, mechanisms, and management. Lancet 1999;353:1959-64.

8. Rolke R, Baron R, Maier C, et al. Quantitative sensory testing in the German Research Network on Neuropathic Pain (DFNS): Standardized protocol and reference values. Pain 2006;123:231-43.

9. Walk D, Sehgal N, Moeller-Bertram T, et al. Quantitative sensory testing and mapping: A review of nonautomated quantitative methods for examination of the patient with neuropathic pain. Clin J Pain 2009;25:632-40.

10. Samuelsson M, Leffler AS, Hansson P. Dynamic mechanical allodynia: On the relationship between temporo-spatial stimulus parameters and evoked pain in patients with peripheral neuropathy. Pain 2005;115:264-72.

11. Samuelsson M, Leffler AS, Johansson B, Hansson P. The influence of brushing force and stroking velocity on dynamic mechanical allodynia in patients with peripheral neuropathy. Eur J Pain 2011;15:389-94.

12. Koltzenburg M, Lundberg LE, Torebjork HE. Dynamic and static components of mechanical hyperalgesia in human hairy skin. Pain 1992;51:207-19.

13. LaMotte RH, Shain CN, Simone DA, Tsai EF. Neurogenic hyperalgesia: Psychophysical studies of underlying mechanisms. J Neurophysiol 1991;66:190-211.

14. Simone DA, Baumann TK, LaMotte RH. Dose-dependent pain and mechanical hyperalgesia in humans after intradermal injection of capsaicin. Pain 1989;38:99-107.

15. Charlton E. Ethical guidelines for pain research in humans. Committee on Ethical Issues of the International Association for the Study of Pain. Pain 1995;63:277-8.

16. Shrout PE, Fleiss JL. Intraclass correlations: Uses in assessing rater reliability. Psychol Bull 1979;86:420-8.

17. Hansson P, Lacerenza M, Marchettini P. Aspects of clinical and experimental neuropathic pain: The clinical perspective. In: Hansson P, Fields H, Hill R, Marchettini P, eds. Neuropathic Pain: Pathophysiology and Treatment, Progress in Pain Research and Management. Seattle: IASP Press, 2001:1-18.

18. Landerholm AH, Hansson PT. Mechanisms of dynamic mechanical allodynia and dysesthesia in patients with peripheral and central neuropathic pain. Eur J Pain 2011;15:498-503.

19. Samuelsson M, Leffler AS, Johansson B, Hansson P. On the repeatability of brush-evoked allodynia using a novel semiquantitative method in patients with peripheral neuropathic pain. Pain 2007;130:40-6.

20. Edin BB, Essick GK, Trulsson M, Olsson KA. Receptor encoding of moving tactile stimuli in humans. I. Temporal pattern of discharge of individual low-threshold mechanoreceptors. J Neurosci 1995;15:830-47.

21. Essick GK, Edin BB. Receptor encoding of moving tactile stimuli in humans. II. The mean response of individual low-threshold mechanoreceptors to motion across the receptive field. J Neurosci 1995; 15:848-64.

22. Shenker NG, Haigh RC, Mapp PI, Harris N, Blake DR. Contralateral hyperalgesia and allodynia following intradermal capsaicin injection in man. Rheumatology (Oxford) 2008;47:1417-21.

23. Bland JM, Altman DG. Comparing two methods of clinical measurement: A personal history. Int J Epidemiol 1995;24(Suppl 1):S7-14.

24. Bland JM, Altman DG. A note on the use of the intraclass correlation coefficient in the evaluation of agreement between two methods of measurement. Comput Biol Med 1990;20:337-40.

25. Atkinson G, Nevill AM. Statistical methods for assessing measurement error (reliability) in variables relevant to sports medicine. Sports Med 1998;26:217-38. 


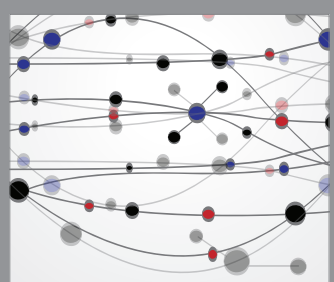

The Scientific World Journal
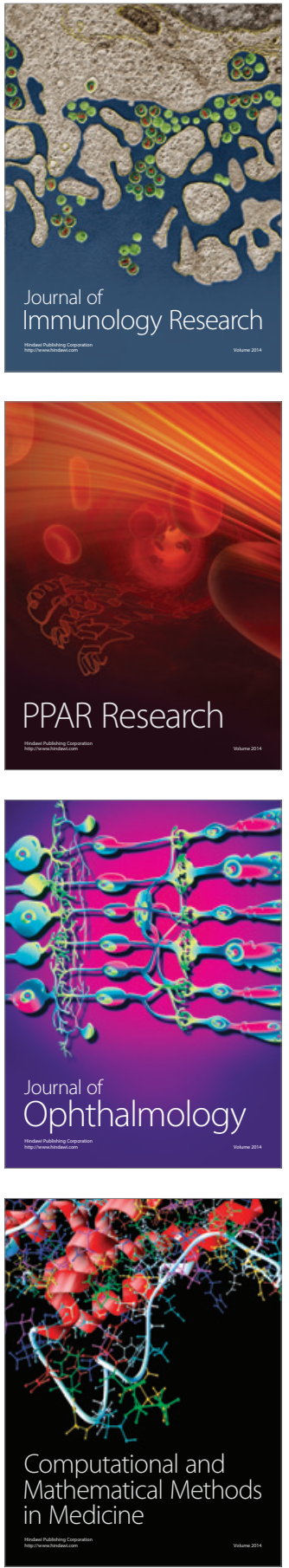

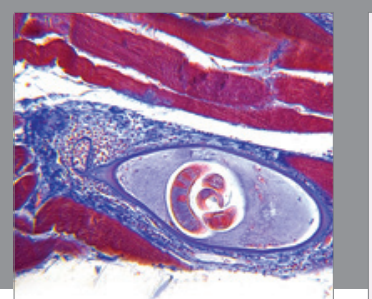

Gastroenterology Research and Practice

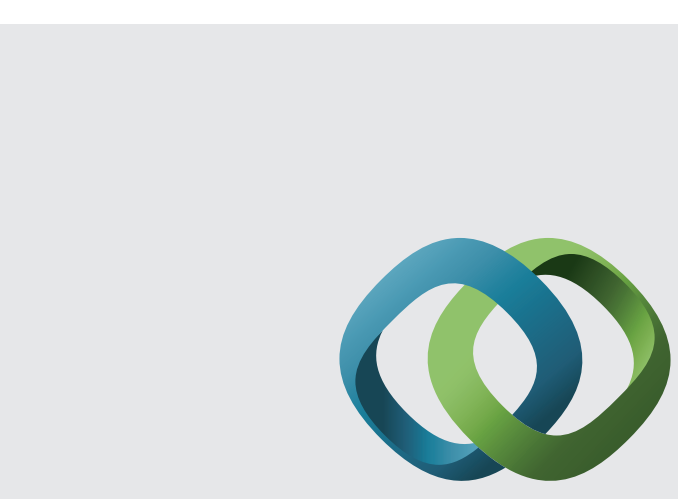

\section{Hindawi}

Submit your manuscripts at

http://www.hindawi.com
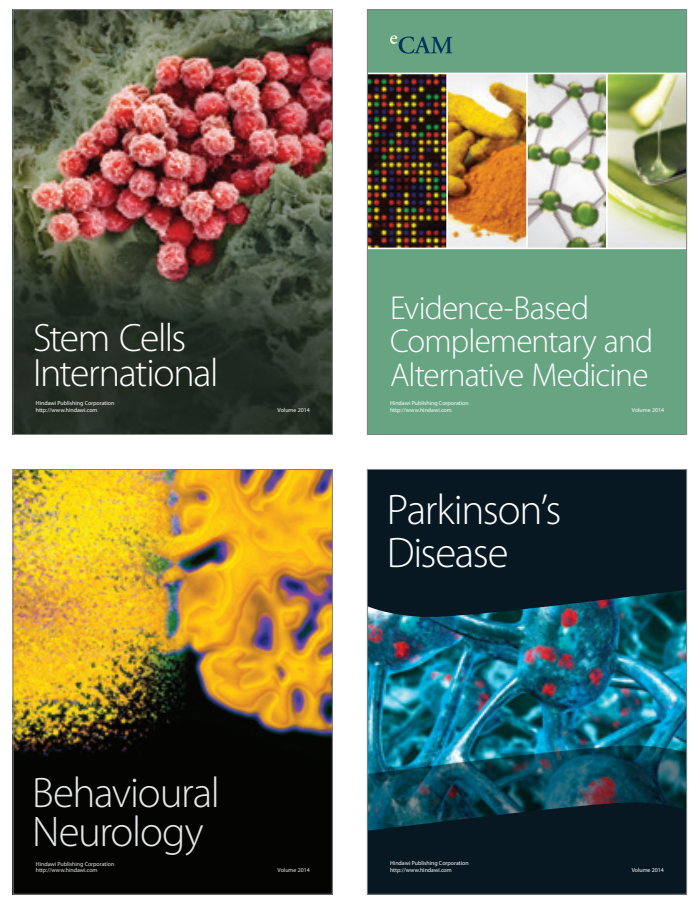
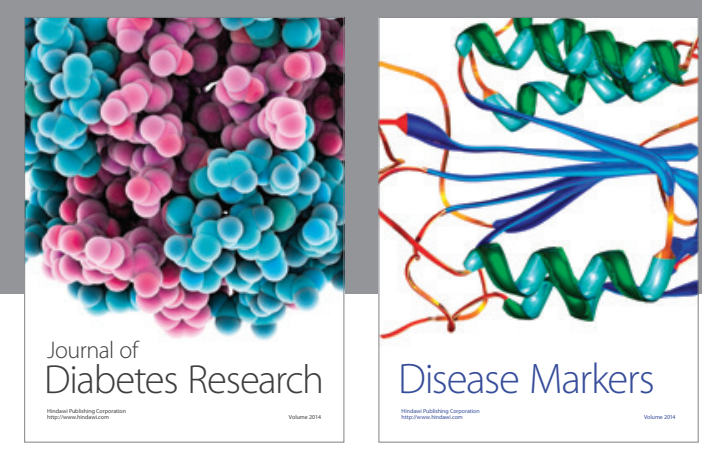

Disease Markers
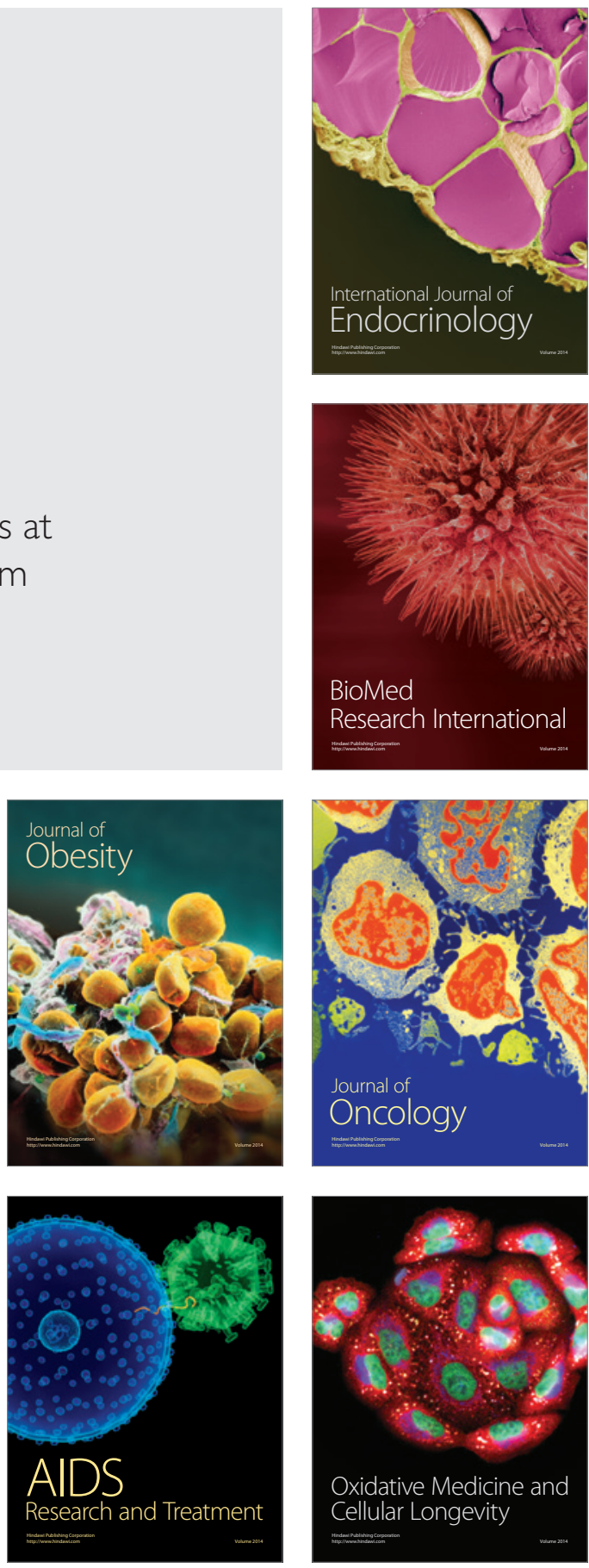